\title{
Uncovering the Effects of COVID-19 Responses on the Lives of Commercial Sex Workers: A Phenomenological Study in Bahir Dar City Administration, Ethiopia
}

Yohannes Mersha Belete ( $\sim$ beletemersha6@gmail.com ) Bahir Dar University

Research article

Keywords: Commercial Sex Workers, COVID-19 Responses, Bahir Dar City Administration and Ethiopia

Posted Date: August 18th, 2020

DOl: https://doi.org/10.21203/rs.3.rs-39483/v1

License: (9) This work is licensed under a Creative Commons Attribution 4.0 International License. Read Full License 


\section{Abstract \\ Background}

The novel coronavirus pandemic is the most shocking and unprecedented human tragedy of the $21 \mathrm{st}$ century, and it is regarded as a human, social and economic crisis. It is affecting every society throughout the world, but some groups of the society are suffering more because of it. Commercial sex workers are one of the groups adversely affected by the measures taken by governments to contain the spread of COVID-19. However, little is yet known about the impact of the coronavirus pandemic on sex workers across the globe. Hence, the main objective of this qualitative study is to shed light on the untold effects of COVID-19 responses on the lives of commercial sex workers by taking Bahir Dar City Administration, Ethiopia as a case in point.

\section{Methods}

To meet the objective of the study, a qualitative method with phenomenology research design was used. Twelve female sex workers were selected through snowball sampling technique. Telephone interviews were held with each of them. The data extracted from the participants were analyzed using thematic qualitative data analysis technique, and member checking system was employed to validate the quality of the data.

\section{Results}

The results indicate that commercial sex workers have encountered unique problems after the enforcement of coronavirus-related regulations and laws. Sex workers have lost their job, and most of them have faced problems to cover their basic need expenses. They are at high risk to be starved in this coronavirus period. Financial problems have forced them to practice unprotected sex and sleep with unhygienic clients. This implies that coronavirus pandemic can be associated with the spread of HIV among sex workers. Their suffering has been further exacerbated by lack of support from the government, stigma at shopping places and structural stigma. Moreover, the nature of their job has exposed them to be easily infected with coronavirus. All these agonies have plunged sex workers into the depths of frustration and anxiety.

\section{Conclusion}

Based on the results of the study, it was concluded that government measures in response to COVID-19 have put many commercial sex workers in a dire situation. This suggests that there is an urgent need to support them and the government should provide economic and social supports to lessen the effects of COVID19 on the lives of sex workers. 


\section{Background}

The novel coronavirus, the acute respiratory infection (SARS-COV-19), was initially identified in the Chinese city of Wuhan in the last months of 2019 (1). It is spreading quickly all over the world since January 2020. WHO declared COVID-19 as a global pandemic on 17 March 2020 (2). After the declaration, most nations of the world are responding to coronavirus by taking various measures ranging from flight restrictions to the total lockdown of major cities $(3 ; 4)$.

Although many countries have taken strict measures to contain the spread of coronavirus, over six million people have been already infected with the virus in 188 countries and more than 350,000 people have lost their lives. It is also projected that many more people will be infected with and die of the virus across the globe (5). Apart from such devastating impacts of the coronavirus on the lives and health of people, it has also an impact on the socio-economic conditions of people. All in all, the novel coronavirus is recognized as a health, social and economic crisis (6).

However, the individual or group level impact of COVID-19 has been overlooked by the responses of governments to contain the spread of the virus throughout the world. Most of the COVID-19 related regulations are enforced in all countries without giving due considerations to the most vulnerable members of the society. Commercial sex workers are one of the groups who suffer a lot due to the COVID19 pandemic. Their suffering is further exacerbated by the long presented public and state-sponsored discriminations perpetrated against them (7)

During World War II, sex workers were detained and quarantined by the government in order to protect soldiers from sexual transmitted diseases. They were blamed for the deaths of many soldiers due to syphilis and gonorrhea (8). After the outbreak of HIV pandemic in 1980's, sex workers have also been blamed for the spread of the HIV and they have encountered crime and discrimination that inflicted by the government (9). Such historical trends have still continued in the coronavirus period since many sex workers across the world have faced forceful quarantine and imprisonment. Although sex workers are severely affected by the novel coronavirus, many governments in the world have not yet shown any interest to provide financial and social support for sex workers. All these facts show that sex workers face a dozen of prejudices whenever there is a global pandemic or disease (7).

Since the first coronavirus case identified in Ethiopia on 13 March 2020, the government has been enforcing some regulations to contain its spread. The measures include shutting down of schools, bars and night clubs, freeing prisoners with minor offenses, postponing of the August national election and large gatherings, and quarantining all incoming travelers for 14 days. In addition, a state of emergency has been declared since 08 April 2020 in Ethiopia. Since many citizens have to work daily to make ends meet, the government does not want to take a harsher lockdown (10). However, the strict restrictions of bars and nights clubs have already impacted the overall wellbeing of sex workers as their livelihood depends on daily incomes. The government has not still taken any measures to mitigate the effects of coronavirus on sex workers. Generally, sex workers in Ethiopia do not get any government support instead they are struggling to survive by their own means (11). 
Moreover, most of the academic and research institutions functioning in Ethiopia have insisted researchers and scientists to only conduct medical investigations that can bring out solutions for COVID19. This indicates that the socio-economic dimension of coronavirus has gotten little attention by researchers not only in Ethiopia but also in the rest of the world (12). Taking the aforementioned problems into account, this study attempted to uncover the untold effects of COVID-19-19 responses on the lives of commercial sex workers in Bahir Dar City Administration, Ethiopia.

\section{Methods}

\section{Description of the Study Area}

Bahir Dar, a city with a total population of 321,000 is the capital of Amhara Regional State in Ethiopia. With an area of 1443.37 square kilometers, the city is located at the exit of the Blue Nile from Lake Tana at an altitude of 1,820 meters above sea level. Bahir Dar is one of the leading tourist destinations in Ethiopia, with a variety of tourist attraction places (13). For its efforts in addressing the challenges of rapid urbanization, the city was awarded the UNESCO Cities for Peace Prize in 2002 (13). In terms of area coverage, the city is divided into 9 sub-cities. Tewodros is the largest sub-city followed by Dagmawi Minillik whereas Gish Abay is the smallest followed by Sefene Selam and Shum Abo sub-cities. The subcities are also divided into 26 kebeles (17 urban and 9 rural kebeles), which are the smallest administrative units in the city (15).

\section{Research Approach and Design of the Study}

A qualitative approach with phenomenological design was employed to explore the effect of COVID-19 responses on the lives of commercial sex workers at Bahir Dar City Administration. The researcher applied this design for three major reasons. The first reason is that this study focused on exploring the lived experience of sex workers and secondly, it tried to explore their hidden experiences. The last but not the least reason is that it attempted to see the experiences of sex workers from their own insight by their own words.

\section{Sampling Technique}

In this study, purposive and snowball sampling techniques were employed to select the area and participants of the study respectively. Bahir Dar City Administration was purposively selected partly because of the availability of sex workers who are affected by the coronavirus pandemic and partly because of the researcher's familiarity with the study area where the researcher has lived and worked for a long time. Among the sub cities on Bahir Dar, Gish Abay and Sefene Selam were purposively selected as study sites because many bars and nightclubs are located in these sub-cities. Regarding selection of participants, the researcher used snowball sampling technique since it is difficult to easily meet sex workers in this COVID-19 period. According Creswell (2019), snowball sampling is more suitable to use when members of the society are hidden or difficult to locate (16). During the coronavirus pandemic, many sex workers are staying at their home since the government has closed night clubs and bars. Within 
this scenario, it was not plausible to apply other non-probability sampling techniques to get sufficient numbers of participants. Needless to say, snowball sampling or respondent-driven sampling technique was employed to select participants of the study. To apply this technique, the researcher initially set out some inclusion criteria to select the participants. The inclusion criteria are: being female, having more than five years working experience, being a regular sex worker at bars or night clubs and having an age greater than 18 years. Based on these criteria, two sex workers were found from Gish Abay and Sefene Selam sub-cities and were asked to find other sex workers who could meet the inclusion criteria. Finally, a total of 12 female sex workers were recruited from these two sub cities through chain-referral sampling technique.

\section{Data Collection Technique and Procedure}

An in-depth interview guideline was prepared initially in English and then translated into the local language, Amharic (See additional file 1). It was pretested before the actual field work. Electronic consent was obtained from each participant since it was difficult to get written consent due to coronavirus. Prior to the interview session, some arrangements were made to find a convenient time for making telephone interview. Appointments were made with the consent of the participants. Based on the agreed-up-on schedule, interviews were conducted with all selected participants via telephone. Each interview lasted for more than two hours. The issues covered in the in-depth interview session include economic, health, social and psychological challenges that sex workers face due to COVID-19. All the interviews were done by the researcher; and their reflections were captured through phone call recorder.

\section{Method of Data Analysis}

The data analysis of phenomenological studies relies on information collected from interviewees. Though this method was lengthy and time consuming, its data could be organized categorically and analyzed thematically. Thus, in accordance with phenomenological research data analysis processes, the following major steps were followed. First, the voices and responses of the participant recorded during the phone interviews were transcribed into text form. While performing this, attentive listening and careful note taking were employed for valid documentation. The transcribed data were translated from Amharic into English (See additional file 2). After the data transcription and translation processes, coding procedure was followed by giving false code numbers for each participant. The coding helps to minimize the researcher's bias in the analysis of the cases. Then, the researcher read the coded text data thoroughly so to be familiar with the information. Afterward, the coded data was categorized into similar or related categories. The categorized data were then converted into themes. Finally, interpretation and analysis were made on each theme.

\section{Data Quality Assurance}

To ensure the quality of the data, the in-depth interview guideline was first prepared and was given through email for experts to comment on the contents, language and overall patterns of the tool. Based on the comments, improvements were made. In addition, the interview guideline was pilot tested on similar participants who were not incorporated in the study. Based on feedback from the participants, the 
tool was further enriched. As the phenomenology study focuses on the lived experience of individuals, the data were exclusively collected through telephone interview method. However, this kind of study has an innate limitation to cross check information by using different qualitative data collection instruments. In addition, a telephone interview method has a limitation to capture non-verbal cues of the participants like body gesture and physical emotions. However, to minimize these limitations, member checking system was utilized. To this end, the participants were communicated again through phone call and briefed them about the result of study and then asked them to confirm whether their real voices were properly captured or not.

\section{Limitations}

It is widely accepted that face-to-face interview is somehow better than telephone interview as it provides visual access for the researchers to capture non-verbal feelings of interviewees. Although telephone interview lacks visual contact between the interviewer and interviewee, it allows interpersonal communication without a face-to-face meeting. Telephone interview is, indeed, the best data gathering tool when there is an airborne disease like COVID-19. With this rationale, telephone interview was used to collect information from the participants. To minimize the limitation of the telephone interviewee, maximum number of samples that are commonly used in phenomenological study were taken. Moreover, getting empirical studies on this topic is very challenging since COVID-19 is a new phenomenon for the researchers. However, maximum effort is exerted to discuss the finding of the present study with previous studies or reports.

\section{Result}

\section{Economic Challenge}

The participants of the study unequivocally disclosed that they are facing financial problem after the government put in place restrictive measures on night clubs and bar houses to respond the coronavirus pandemic. The economic challenges facing commercial sex workers due to the crisis are classified into two as are detailed below.

\section{Unable to get money}

Almost all commercial sex workers face loss of income and become increasingly vulnerable due to the government responses to contain the spread of coronavirus. As they reported, the federal government has shut down bars and night clubs since the report of the first coronavirus case in Ethiopia on march 13. However, this regulation had not been strictly implemented in Bahir Dar City Administration until the first coronavirus case was found in the city on 27 March 2020. Since the Amhara regional government has stringently enforced the rule of the shutdown of bars and night clubs on March 27, almost all sex workers lost their job and face difficulty to earn money. This situation is well articulated by the verbal account of the following participant; 
I have been working as a commercial sex worker for more than 10 years. Over this period, I have never suffered severe economic hardship like the case I am facing after the corona outbreak. It is almost two months since I met a client and earned money. The government considers sex workers as a social disease, and because of this stereotype the government does not show any interest in providing economic support for us during this pandemic period. (Participant 1)

In the same vein, another participant expressed the incident as:

All bar houses and night clubs are in a complete lockdown following the government's measure to prevent the spread of coronavirus in the city. Therefore, I can't go to bars. If I do not go to bars, I do not get clients. If I do not get clients, I do not get money. I am now leading my life by spending a few amounts of money I saved before. If I do not go back to work within a few days, I will be starved to death. (Participant 2)

The above reflections indicate that the government's restrictions of bars and night clubs to respond to COVID-19 have brought devastating economic impact on commercial sex workers since it has left almost all commercial sex workers out of work. The results also indicate that most of them do not have any money to buy food. Given this condition, it can be concluded that commercial sex workers are at high risk to die from hunger unless the government takes supportive measures for them.

\section{Working with low price}

The results of the study also indicated that commercial sex workers are economically affected by the pandemic. Although the majority of commercial sex workers are unable to do sex business due to the government's responses to COVID-19, few of them are still working since some of their clients can meet them through phone call at home. However, the coronavirus response measures of the government have impacted the price bargaining power of those commercial sex workers who were able to work during the pandemic period. The price of sexual service has declined sharply after the outbreak due to clients dwindle. In connection to this idea, one of the participants of the study said:

After the corona outbreak, it is very difficult for me to get clients. But I am fortunate that few of my clients have my cell phone number. Therefore, they are able to get me at home. However, they do not want to pay me the usual amount for the service I render because they know very well that I do not have other options to refuse that low price. (Participant 3)

Similarly, another participant noted:

I am suffering from serious economic problem since after the first corona case reported in the city. I do not have enough money for food and I sometimes get hungry. As long as my clients agree to cover my daily meal, I am willing to offer sexual service for them, without asking an additional payment. I know the risk of coronavirus, but I will die if I do not eat food. Now, I worry more about how to survive than the infection of coronavirus. (Participant 4) 
From the above reflections, it could be comprehended that few numbers of commercial sex workers are still working at their home but they get lower price compared to the pre-pandemic prices. The result also informs us that sex workers are putting themselves at risk of contracting coronavirus just for getting money to buy food. This leads to the conclusion that, for sex workers, the risk of chronic hunger is becoming more dangerous than coronavirus.

\section{Health-related Challenges}

Given that sex work is a contact job, commercial sex workers are at high risk to be infected with coronavirus. Apart from this common health risk, sex workers encounter other health risks due to the government's responses to curb the spread of coronavirus in the nation. The findings of the study revealed that the COVID-19 responses have forced sex workers to practice unsafe sex and sleep with unhygienic clients. These health challenges are discussed as follows.

\section{Forced unsafe sex practice}

According to the information elicited from the participants, the government's measures have impacted commercial sex workers to adapt to unprotected sexual practices in order to survive. They started to give sexual services like oral sex and sex without condom since they are competing for few clients due to the pandemic. Explicating this issue, one of the participants of the study said:

Some clients request us to make oral sex while some others ask to have sex without condom. I know very well that these sexual practices can expose us for different kinds of sexually transmitted diseases including HIV/AIDS. I had previously refused such kinds of sexual requests. After the outbreak of the corona pandemic, I become careless to protect myself from such kinds of unsafe sexual intercourses. You know why... I would lose my clients if I did not fulfill their sexual needs. At this time, I do not want to lose my clients because I am now struggling to cover my daily meal and house renting expenses. (Participant 5)

Another participant shared her shocking story as:

I am living with HIV. When some clients demand unprotected sex, I advise them not to do it. But, if they do not accept my advice, I offer them unsafe sexual service because I cannot survive in this pandemic period unless I make some money. Previously, I did not practice unprotected sex in order to protect my clients from HIV virus but after the coronavirus outbreak, I could not protect some of my clients from HIV infection as I do not have any other option for survival. (Participant 6)

The above narrations clearly asserted that sex workers are enticed into unprotected sex work because of the coronavirus pandemic. Sex workers operating in the city are aware of the risk of sexually transmitted infections of unsafe sex, but they are now practicing unprotected sex as they are desperate for money due to the impact of COVID-19. It is also hard for HIV-positive sex workers to put off clients who only need unsafe sex. This implies that COVID-19 contributes to the spread of HIV/AIDS among sex workers and their clients. The results also inform us that sex workers are doing their business by putting themselves at 
the risk of contracting the coronavirus. It can be, therefore, concluded that sex workers are more exposed for both HIV/AIDS and coronavirus infections in this COVID-19 period.

\section{Forced sleep with unhygienic clients}

According to the reflection of the participants, sex workers had often refused their perceived untidy clients. When they encounter sexual partners, who have bad smells or not wearing clean cloths, they immediately ignored them and looked out for another client. Such habit of sex workers had been demonstrated during the pre-coronavirus period. After the outbreak of this global pandemic, they do not choose their clients by taking personal hygiene as a criterion. This idea is further elaborated by the verbatim account of the following participant:

I would not sell sex only for money instead I need to also enjoy myself. Previously, I only chose clients with good personal hygiene since I would not enjoy having sex with unhygienic clients. But after the corona pandemic, I sleep with clients who are untidy since I do not have other options to get money. It is disgusting to share a night with clients whose shoes or breaths have bad smells. (Participant 7)

As it is unveiled in the above case story, COVID-19 has impacted the right of sex workers to freely choose their clients. This scenario would in turn force them to sleep with clients who have unpleasant smell like funky breath, stinky underarm and feet odor since they desperately seek money to feed themselves.

\section{Social Challenges}

The result of the study showed COVID-19 related stigma against commercial sex workers. Based on its nature, the stigma is classified into two.

\section{Shopping place stigma}

As per the results of the study, social stigma against sex workers is ramping up because of the government's response to the coronavirus pandemic particularly in the time of the complete lockdown of Bahir Dar city which lasted for a couple of weeks. The participants mentioned that they had experienced stigma at shopping places and the offenders were both sellers and buyers. In light of this idea, one of the participants shared her experience as follows;

When Bahir Dar city was under a strict lockdown for two weeks, people were allowed only to buy various commodities from the nearby shops located at resident places. During that time, I went to a shop to buy onions and potatoes with one of my workmates. The owner of the shop had warned us: "Do not come again to my shop". I asked him to tell me the reason why he said that. He replied: "You are highly susceptible to coronavirus since you have many foreign clients". (Participant 8)

Similarly, another participant said;

Bahir Dar city went into full lockdown for two weeks immediately after one corona case was identified. I always experienced stigma when I went to shopping places. The perpetrators were both sellers and 
buyers. They showed me unwelcoming non-verbal gestures. They made me feel as if I were a coronavirus carrier. (Participant 9)

From the above verbal account, one could discern that the complete lockdown of the city exposed sex workers to experience stigma at shopping centers. This happened because of the societal stereotype that claims sex workers as the main agents to spread coronavirus.

\section{Structural stigma}

Based on the findings of the study, sex workers are subjected to stigmata because of the outbreak of coronavirus. Though the government has enforced a law that gives the poor and marginalized people the right to get 50 percent reduction of house rent to cope up with the economic impacts of COVID-19, the law is not properly working when it comes to sex workers. Many sex workers have not still benefited from this law rather they have been forced to pay double for house rent. They are facing this problem just because of the reluctance of legal bodies to support sex workers. Their interactions with the police have also been rather marred with threats including physical and verbal harassment. The police officers have inflicted verbal and physical abuse against sex workers with the pretext of violating COVID-19 rules and regulations of the government. In conjunction with these problems, one of the participants recounted:

During the lockdown, the police officers had warned me and my colleagues not to move from place to place. However, the police officers did not give similar warning to other people. This is a clear discrimination perpetrated against commercial sex workers. Some of my friends had also experienced physical beating by police officers for violating the rule of stay indoors. (Participant 10)

Another participant added,

The government has announced a 50\% reduction of housing rent due to the coronavirus pandemic. Many people have benefited from this. As opposed to this announcement, many house owners have doubled the monthly rental price on commercial sex workers in order to push us to leave their houses. We have reported this crime at the police station and local authority office. None of these institutions have shown interest to investigate our complains instead they consider us as the enemies of social order. (Participant 11)

As it is illuminated from the above quotations, sex workers have been stigmatized by the legal bodies and local governors in the COVID-19 period. They are mistreated and sometimes physically abused by government bodies. They have not also enjoyed the financial incentive that was announced by the government after the outbreak of the pandemic. Generally, it can be concluded that the coronavirus pandemic has intensified the stigmatization and discrimination of sex workers.

\section{Unable to get social protection}

The results of this study indicated that the Ethiopian government and some volunteer individuals or groups have distributed food and shelter packages to poor and vulnerable groups who are elders, beggars and street children/youths as a response to the pandemic. The government has also taken some 
economic measures for its citizens to minimize the financial effects of the pandemic. However, commercial sex workers are forgotten in such responses to the COVID-19 though they are at a great risk of being infected with coronavirus. In light of this idea, one of the participants of study put the following remark;

We heard that the government and some private organizations have donated food items, soaps and hand sanitizers for economically vulnerable groups who are elders, street youths or children and beggars. Even the government has provided hand sanitizers and masks for public servants free of payment. The government has also recently announced that it will take tax related measures to mitigate the effects of coronavirus on traders. However, the government and other agencies have not still taken any measures to support commercial sex workers though we are the most affected group by the crisis. (Participant 12)

From the above case story, we could comprehend that sex workers cannot access government support during the COVID-19 pandemic unlike other citizens. Therefore, it can be concluded that commercial sex workers are the most abandoned group of the society in the coronavirus pandemic period.

\section{Psychological problems}

Based on the result of the study, COVID-19 has also a psychological impact on sex workers. When sex workers are out of job with no financial relief, they panic and become hopeless. Feeling of dizziness has also been experienced by those sex workers who have substance abuse problem. These problems are concisely presented as follows;

\section{Feeling of dizziness}

The participants of the study elucidated that sex workers are more vulnerable to substance addiction due to the nature of their occupation. The majority of them are drug or alcohol dependent. Due to the corona pandemic, sex workers have lost their income and they do not have the money to buy substances. This implies that sex workers are instantly forced to quit substance use though addiction is a chronic disease that requires treatment. Therefore, sex workers experience immediate addiction disorders like feeling of dizziness due to lack of treatment. In connection to this idea, one of the participants divulged that;

I am addicted to khat (Stimulant). When my work place is totally shutdown due to corona pandemic, I cannot use substance daily because I don't have money to buy it. I feel dizzy when I do not chew khat. I have now started to hate myself and sometimes I wish to die. (Participant 2)

In the same token, another participant said;

I had considered the shutdown of my work places as a good opportunity to cure myself from cigarette, alcohol and khat addictions. I tried to stop consuming these substances, but it is not as such simple and I could not cope with health symptoms such as moodiness, irritability and severe headache. I get worried when I do not have money to buy substances. I prefer to use substance instead of experiencing dizziness. I am now thinking that I can be only cured from addiction with holy water if it is God's will. (Participant 9) 
The above reflections inform that the shutting of bars and night clubs has dissolved the daily income of sex workers and because of this financial problem, they do not meet their daily intake of substances. Although the pandemic may have a positive impact to be cured from their addiction behaviors, they do not get access of medical treatment and counseling that could help them to recover with a proper manner. Hence, substance addicted sex workers experience feeling of dizziness and nervousness when they do not get substances.

\section{Being hopeless}

The results of the study indicated that sex workers have been hit hard by the closure of bars and night clubs due to coronavirus crisis. They are not able to pay rent and afford basic necessities. It is also very difficult for them to find other jobs. All these problems could make them hopeless and helpless. Concerning this issue, one of the participants shared her story as follows;

Due to the corona virus response, it has been almost two months since I got money. By now, I have no money. There are no food items and other consumable goods like soaps in my home. I am severely starved. To add fuel to the fire, my house renters are always nagging and intimidating me as I failed to pay the amount of rent that is due every month. I have attempted to find jobs like waitress and domestic work but all my attempts have remained futile. When I encounter all these problems, I feel empty and become hopeless. I am not sure for how long I live like this. The only hope that I have is the government will soon lift the shutdown of night clubs and I will then get back to my job. If things are not happening the way I think, I will die with hunger. (Participant 1)

As it is clearly reflected in the above case story, the government measure to COVID-19 has left sex workers in terrible situation which induces panic and hopelessness. Compounded with the failure of the government to provide financial support for sex workers, they are in danger to survive.

\section{Discussion}

The present study found out that commercial sex workers are suffering from the economic consequences of coronavirus. Since sex workers have fewer or no clients due to the pandemic, they are facing a total loss of income and getting difficulty to cover their basic need expenses. Similarly, UNAIDS (2020) reported that sex workers have been hit hard by the pandemic throughout the world (7). The Global Network of Sex Work Projects (GNSWP) and UNAIDS also jointly reported that sex workers and their families around the world are facing a problem to access basic necessities because of COVID-19 (7).

As it was reported in the present study, the coronavirus pandemic impacted commercial sex workers to practice unprotected sexual intercourse and meet unhygienic sexual clients, and they are at high risk to be infected with HIV and COVID-19. Similarly, GNSWP (2020) reported that sex workers are still continuing their business in some Asian and African countries though coronavirus is a big threat for their lives. They do not want to refuse when their clients request unprotected sex as they have serious economic dearth due to the pandemic (7). Unlike the findings of the present study, in person sex work has been almost 
halted in many countries because of the strict physical-distancing measures and the shutdown of bars and night clubs to contain COVID-19.

The present study indicated that sex workers have experienced stigma at shopping places and they have also been mistreated by police officers and local governors in this crisis period. UNAIDS (2020) also reported that Kenyan sex workers have been forcefully quarantined and detained for violating social distancing rules. Many sex workers in different countries have been stigmatized and arrested for not adhering to the COVID-19 rules and regulations of the government. This implies that the coronavirusrelated institutional stigma against sex workers exists all over the world though the nature and the degree of stigma varies from place to place (15).

As per the results of the present study, sex workers have not yet received support from the government even though they have lost their job due to the pandemic. As opposed to this finding, it is reported that the Japanese government is offering sex workers financial aids though it is not satisfying the demands of sex workers (15). Some other countries have also implemented support package to reduce the impact of the pandemic on sex workers. For instance, sex workers in Bangladesh had their rent suspended and received 20 to 30 kilograms of rice (16). However, majority of sex workers in the United States did not get support from the government and other social institutions (7).

According to the results of the present study, sex workers have faced psychological problems such as feeling of dizziness and hopeless due to the government measures to contain the spread of COVID-19. Likewise, the Global Network of Sex Work Projects reported that sex workers in Bangladesh have become desperate and hopeless due to complete lockdown of brothels to fight the spread of coronavirus in the country. They are struggling to survive since the pandemic leaves them with serious financial dearth. Sex worker right organizations also reported that sex workers in all over the world are being frustrated when they suddenly loss their job due to Covid-19 (15).

\section{Conclusion}

Based on the results of the study, it was concluded that there are various challenges that commercial sex workers face due the government's response to COVID-19. The most common challenges are severe economic problem, unprotected sexual practice, forced sex with unhygienic clients, being exposed to coronavirus infection and HIV, stigma at shopping places, structural stigma and psychological problems. Although sex workers are more vulnerable to the novel coronavirus, they want to continue their job hiddenly as they do not have alternative survival means. It was also concluded that commercial sex workers have not been entitled to have the government support available to others during the COVID-19 crisis though they should have to get more governmental support since the restriction measures have a devastating and long-lasting effect on their livelihood. Generally, it was concluded that commercial sex workers cannot survive in this novel coronavirus era unless the government provides them with aid in its various forms. 


\section{Abbreviations}

AIDS

Acquired Immuno-deficiency Syndrome

HIV

Human Immunodeficiency Virus

NSWP

Global Network of Sex Work Projects

UN

United Nations

UNAIDS

Joint United Nation Programs on HIV/AIDS

UNESCO

United Nations Educational, Scientific and Cultural Organization

\section{Declarations}

\section{Ethics approval and consent to participate}

In order to comply with code of ethics of research, this particular study was begun by assuring letter of ethical approval from Bahir Dar University Ethical Clearance Committee. Following the ethical approval, the participants were informed through phone conversation about the purpose and other issues pertinent to the study. Then, electronic consent was gained from each participant. In order to preserve anonymity and confidentiality of the participants, codes were used instead of real names. In addition, any individual participant identifiers were totally removed from the report of the study. Additionally, convenient time for making telephone interviews was arranged based on the interest of the participants. Crucial measures and cautions were taken not to inflict any harm, inhumane treatment and deceptions on the participants during phone interviews. A great effort is made to report only the real findings of the research without distortion and omission.

\section{Consent for publication}

Not applicable.

\section{Availability of data and material}

All data generated from this study are available in the published article and its supplementary information files.

\section{Funding}

The study had not been donated by any donor agency. 


\section{Competing interests}

The author has not declared any conflict of interests.

\section{Author's contribution}

YMB had collected the data and written the entire manuscript.

\section{Acknowledgements}

I would like to thank all research participants for devoting their precious time to share their life experiences.

\section{References}

1. European Centre for Disease Prevention and Control. Rapid Risk Assessment: Outbreak of acute respiratory syndrome associated with a novel coronavirus, Wuhan, China; first update. s.I. : ECDC, 2020.

2. Spinney, Laura. Why did the World Health Organisation wait so long to declare coronavirus a pandemic? s.I. : Newstatesman, 2020.

3. European Centre for Disease Prevention and Control. Coronavirus disease 2019 (COVID-19) pandemic: increased transmission in the EU/EEA. Stockholm : s.n.

4. Rawaf, Salman , Yamamoto, Harumi and Rawaf, David. Unlocking towns and cities: COVID-19 exit strategy. x, s.I. : World Health Orgnanization, 2020, Eastern Mediterranean Health Journal, Vol. xx.

5. Worldometer. Worldometer's COVID-19 data. 2020.

6. United Nations. Everyone Included: Social Impact of COVID-19. 2020.

7. UNAIDS. Sex workers and Clients. s.I. : UNAIDS, 2020.

8. Whitton, Kyra. Women as Subject and Audience in World War II Venereal Disease Poster. s.I. : kennesaw State University, 2010.

9. Women prostitutes in the AIDS era. Scambler, Graham, et al. 3, 1990, Sociology of Health \& IIIness, Vol. 12.

10. Ermias, Tesfaye. Ethiopia's COVID-19 quandary. s.I. : Ethiopia Insight, 2020.

11. ANRS BOWCYA (Amhara Regional State Bureau of Women, Children and Youth Affair). Vulnerable Groups and COVID-19 in Amhara Region. Bahir Dar : BOWCYA, 2020.

12. Tamrat, Wondwosen . Lessons from the shutdown - How one university responded. s.I. : University World News, 2020.

13. BoFED, Bureau of Finance and Economic Development. Economic and Development Report of Addis Ababa City Adminstration. Addis Ababa : BOFED, 2019.

14. UNESCO Institute for Lifelong Learning. Bahir Dar, Ethiopia - UNESCO Learning City Awardee 2015. S.I. : UNESCO. 
15. Bahir Dar City Mayor Office. Bahir Dar City Demographic Report. Bahir Dar : s.n., 2017.

16. Creswell, John. Research Design: Qualitative, Quantitative and Mixed Method Approach. New York : SAGE Publication, 2013.

17. Global Nerwork of Sex Work Project. Promoting Health and Human Rights. s.I. : nswp.

18. Yeung, Jessie, Junko, Ogura and Ripley, Will. Japan: Sex workers say COVID-19 relief package is inadequate, pointing to unclear eligibility rules. s.I. : Business and Human Rights Resource Centre, 2020.

19. UNAIDS. Sex workers in Bangladesh: building resilience during the COVID-19 pandemic. s.I. : UNAIDS, 2020 .

20. Platt, Lucy, et al. Sex workers must not be forgotten in the COVID-19 response. s.I. : LANCET, 2020.

21. UNAIDS. Sex workers must not be left behind in the response to COVID-19. Geneva : UNAIDS, 2020.

22. Farooq, Muhammad. Qualitative telephone interviews: Strategies for success. s.l. : University of Waikato, 2015.

\section{Supplementary Files}

This is a list of supplementary files associated with this preprint. Click to download.

- AttachecedFile1.docx

- AttachedFile2Revisednew.docx 